\title{
Ultrasonic Tissue Characterization with Common B-mode Device: GLHW
}

\section{Kazuo Maeda*}

Department of Obstetrics and Gynecology (Honorary Professor), Tottori University Medical School, Yonago, Japan

Medical ultrasound is superb in the real-time B-mode, transvaginal scan, 3-4D ultrasound, for the morphological examination and diagnosis. Only the Doppler ultrasound is unique in the functional study of blood flow and fetal movement. Although the advanced ultrasound detected the nature of tissue structure in the brightness, back scatter, texture and so on, the technique needed advance computer and programs, so that most ultrasound user are out of the benefit of tissue characterization, for example, ovarian malignancy is still diagnosed by the B-mode patterns. Maeda searched for stable technique for the $\mathrm{B}$-mode brightness and found the histogram of B-mode brightness, which was easily found in every B-mode machine. However, the mean gray level value changed when the sensitivity was controlled, the contrast of B-mode image changed, and when the subject depth was changed, in the studies with an ultrasound phantom in around 1990. The author then studied the standardization of histogram, and found the histogram base width was stable to the sensitivity control. Then the histogram base width was standardized by dividing with full length of the brightness, and the gray level histogram width (GLHW) value was completed. As the GLHW was not influenced by the sensitivity control, but changed by image contrast, the contrast level was fixed at 2 among multiple levels. The GLHW was stable among various B-mode devices, but a machine was tested using the ultrasound phantom. Now the GLHW could be applied for the tissue characterization with common B-mode machine without special computer or program [1]. The region of interest (ROI) of subject image was $1 \times 1 \mathrm{~cm}$ in the trial study, but found the ROI size did not influence on the results. Automatic determination was investigated and confirmed no difference to the manual determination. The automation was introduced into the histogram analysis of Aloka B-mode machine, which was expressed by "\% W" sign in Aloka histogram analysis at the same time with mean and SD of simple gray level. The $\% \mathrm{~W}$ value was adapted to the studies on the fetal lung tissue maturity, recognizing its utility.

1) The first trial of GLHW was studies on ovarian benign and malignant masses using connecting 5 ROIs of the mass Kihaile PE and Maeda K $[1,2]$. Coefficient of variation (CV) was large in benign and small in malignant masses, whereas GLHW was larger in malignant masses than benign. Both groups were clearly differentiated by the CV and GLHW. The levels of teratoma were between benign and malignant masses. A uterine cervical cancer in tumor formation showed larger GLHW than 50 Maeda K [1].

2) The GLHW of benign endometrial hyperplasia was larger than normal endometrium, and the GLHW of endometrial cancer was larger than endometrial hyperplasia and larger than 50 (Ito T). A malignancy may be suspected when the GLHW was larger than 50. Normal adult liver GLHW was measured [1]. Hepatic cell malignancy will be the subject of GLHW study.

3) Placental GLHW was measured in every weeks of pregnancy [2]. Grade 3 placenta GLHW was definitely larger than normal placenta. A $2^{\text {nd }}$ trimester IUGR was higher than normal placenta, where fibrin deposit in the intervillus space was diagnosed and the GLHW was returned to normal, fetal estimated weight increased to normal and normal neonate was obtained after the continuous 5,000 $\mathrm{U}$ of Heparin injection to the mother who had positive antigen, while the fetus died in previous pregnancy (Utsu M) [1].
4) Since the GLHW of stained amniotic fluid was similar to that of fetal colon content, and significantly larger than the normal and clear amniotic fluid [3]. It is clear that the amniotic fluid was stained by fetal meconium discharged by increased colon motion through the loose anal muscle in fetal hypoxia.

5) Fetal periventricular echo density (PVE) was a white echogenic periventricular tissue of fetal brain in B-mode image, which was confirmed by higher GLHW than normal brain in the transvaginal scan, and preceded neonatal periventricular leukomalacia (PVL) and cerebral palsy (CP) in $19 \%$ of persisted PVE in preterm fetus until the preterm births [3].

6) The immature fetal lung followed by neonatal respiratory distress syndrome (RDS) has been diagnosed by the chemical or physical properties of amniotic fluid obtained by the amniocentesis so far, but the amniocentesis accompanied possible risk of fetal demise or other complications. Recently the immature fetal lung preceding neonatal RDS after birth was correctly diagnosed for $96 \%$ by the GLHW of fetal lung and liver in preterm pregnancy. The ROIs are placed at fetal lung and liver, and the ratio of GLHW values of fetal lung and liver was obtained, then the product of lung and liver GLHW ratio and the weeks of pregnancy was determined. The immature fetal lung to be neonatal RDS was diagnosed when the value was less than 29 with the sensitivity of $96 \%$. The area under curve (AUC) of ROC was 92 [4]. Since fetal liver GLHW was constant during pregnancy its ratio to fetal lung was a valuable standardization, and also it will delete the interdevice difference of GLHW values. Thus, the ratio to fetal liver GLHW is recommended in fetal GLHW investigation. The GLHW study on immature fetal lung is useful because of the same sensitivity as invasive amniocentesis, but also by the protection of the fetus from the risk of invasive amniocentesis, i.e. the GLHW method can be repeated in the same fetus for the monitoring of fetal lung maturity, and for the evaluation of steroid therapy for the preterm fetus. The amniocentesis can be replaced by ultrasonic tissue characterization with GLHW for the diagnosis of fetal lung maturity. The non-invasive technique is very useful in fetal medicine.

\section{References}

1. Maeda K, Utsu M, Kihaile PE (1998) Quantification of sonographic echogenicity with grey-level histogram eidth: a clinical tissue characterization. Ultrasound Med Biol 24: 225-234.

*Corresponding author: Kazuo Maeda, Department of Obstetrics and Gynecology (Emeritus), Tottori University Medical School, Yonago, Japan, 3-125, Nadamachi, Yonago, Tottoriken, 6830835, Japan, Tel: 81-859-22-6856; Fax: 81-859-22-6856; E-mail: maeda@mocha.ocn.ne.jp

Received October 22, 2013; Accepted October 23, 2013; Published October 28 2013

Citation: Maeda K (2014) Ultrasonic Tissue Characterization with Common B-mode Device: GLHW. J Health Med Informat 5: e114. doi:10.4172/21577420.1000 e114

Copyright: (c) 2014 Maeda K. This is an open-access article distributed under the terms of the Creative Commons Attribution License, which permits unrestricted use, distribution, and reproduction in any medium, provided the original author and source are credited. 
Citation: Maeda K (2014) Ultrasonic Tissue Characterization with Common B-mode Device: GLHW. J Health Med Informat 5: e114. doi:10.4172/2157$7420.1000 \mathrm{e} 114$

Page 2 of 2

2. Kihaile PE (1989) Ultrasonic tissue characterization of ovarian tumors by the scanning of grey-level histograms. Yonago Acta Medica 32: 251-260.

3. Yamamoto N, Utsu M, Serizawa M, Ohki S, Murakoshi T, et al. (2000) Neonatal periventricular leukomalacia preceded by fetal periventricular echodensity Fetal DiagnTher 15: 198-208.

4. Serizawa M, Maeda K (2010) Noninvasive fetal lung maturity prediction based on ultrasonic gry level histogram width. Ultrasound in Med Biol 36: 1998-2003. 